\title{
LATE RESULTS OF THE OPERATION FOR COARCTATION IN THE GROWING CHILD*
}

\author{
BY \\ J. A. NOORDIJK, F. T. I. OEY, and H. M. P. VAN DEN BOOGAARD \\ From the Department of Thoracic Surgery, Leyden University, the Netherlands
}

There are only incidental published reports on the late results of operations for aortic coarctation in growing children, since the first operations for this anomaly were not performed until 1944 .

Animal experiments have shown that an anastomosis in the aorta, if established with knotted sutures, increases in size with the remainder of the aorta as the animal grows (Johnson and Kirby, 1950). These experiments, however, were carried out with a normal healthy aorta, and warrant no conclusions concerning the growth of the anastomosis following resection of a coarctation in an infant.

Now that the trend is more and more in favour of operating on very young children with imminent cardiac decompensation as a result of a coarctation (Waterston, 1961; Morris, Cooley, de Bakey, and Crawford, 1960; Kempton and Waterston, 1957), it seems important to follow up the results of resection of the stenotic part of the aorta with end-to-end anastomosis (Moss, Adams, O'Loughlin, and Dixon, 1959).

\section{Subjects and Methods}

For inclusion in the follow-up series we decided that the patient's operation should have taken place six years ago or earlier, and that at the time of operation the patient should have been no older than 12 years.

Among a total of over 500 operations for coarctation, 45 met this requirement. Of these 45 patients, 36 were seen for follow-up, 4 are at present living abroad, and 5 failed to report.

The interval between operation and follow-up varied from 6 to 11 years.

Of the patients seen for follow-up the youngest was a year old and the oldest was aged 12 at the time of operation. There were 3 patients between 0 and 2 years, 5 between 2 and 6 years, and 28 between 6 and 12 years. The weight gain averaged $20 \cdot 8 \mathrm{~kg}$. (minimum $5 \cdot 7 \mathrm{~kg}$. and maximum $40 \cdot 2 \mathrm{~kg}$.). The gain in height averaged 33.6 $\mathrm{cm}$. (minimum $13 \mathrm{~cm}$. and maximum $58 \mathrm{~cm}$.).

* A paper read at a meeting of the British Association of Paediatric Surgeons in Rotterdam, September 1964.

\section{Results}

The object of resecting an aortic stenosis is (1) to abolish the stenosis; (2) to reduce the brachial systolic blood pressure; and (3) to reduce the brachial diastolic blood pressure.

Abolition of Stenosis. The causes of death in coarctation not surgically treated are known to be: rupture of an aneurysm in an intercostal artery; sepsis as a result of aortitis; rupture of the aorta; cardiac decompensation; and rupture of an aneurysm in one of the basilar arteries (Reifenstein, Levine, and Gross, 1947).

Resection of the stenosis prevents formation of aneurysms and reduces the risk of aortitis.

At the operation photographs were taken, first of the stenosis and then of the anastomosis; and the circumference of the anastomosis and that of the aortic arch was measured.

We thought it unjustifiable to obtain aortograms merely for the sake of a follow-up, so consequently we have no exact data on the size of the anastomosis at the time of the follow-up. The blood pressure was determined in the arms and in the legs in all follow-up patients. In 33 patients, an external femoral artery curve was plotted. In normal subjects the duration of the ascent is less than $0 \cdot 14$ second. In patients with coarctation this is increased (over $0.16 \mathrm{sec}$.) or cannot be registered.

In 33 patients a femoral artery curve was registered. Only one of these showed unmistakable retardation (ascent $0.25 \mathrm{sec}$.) (Fig. 1), while one showed dubious retardation $(0 \cdot 14-0 \cdot 18 \mathrm{sec}$.).

In 34 of the 36 patients examined, the systolic blood pressure in the legs proved to be equal to or higher than that in the arms. Only in the 2 patients already mentioned was the systolic blood pressure in the leg lower than that in the arm, namely, Case A, whose arm pressure was $130 / 60$, and leg $95 / 60 \mathrm{~mm}$. $\mathrm{Hg}$, and ascent femoral artery curve $0 \cdot 25 \mathrm{sec}$., and Case B, whose arm pressure was 160/90, and leg 


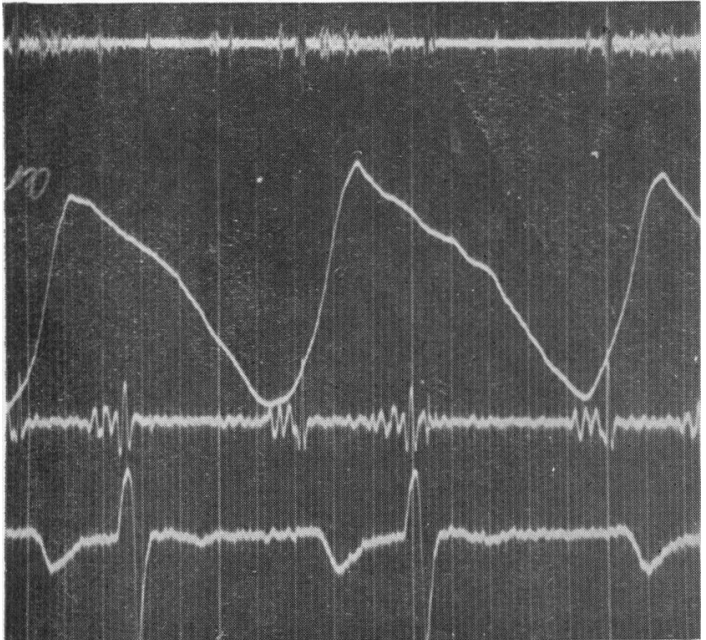

FIG. 1.-Femoral artery curve. The interval between two fine lines is $0.02 \mathrm{sec}$. Normal values for duration of ascent are $0.14 \mathrm{sec}$. Here it is clearly retarded $(0 \cdot 25 \mathrm{sec}$. $)$.

$130 / 115 \mathrm{~mm} . \mathrm{Hg}$, and ascent femoral artery curve $0 \cdot 14-0 \cdot 18 \mathrm{sec}$.

Case A is a boy who was operated on in 1954 , at

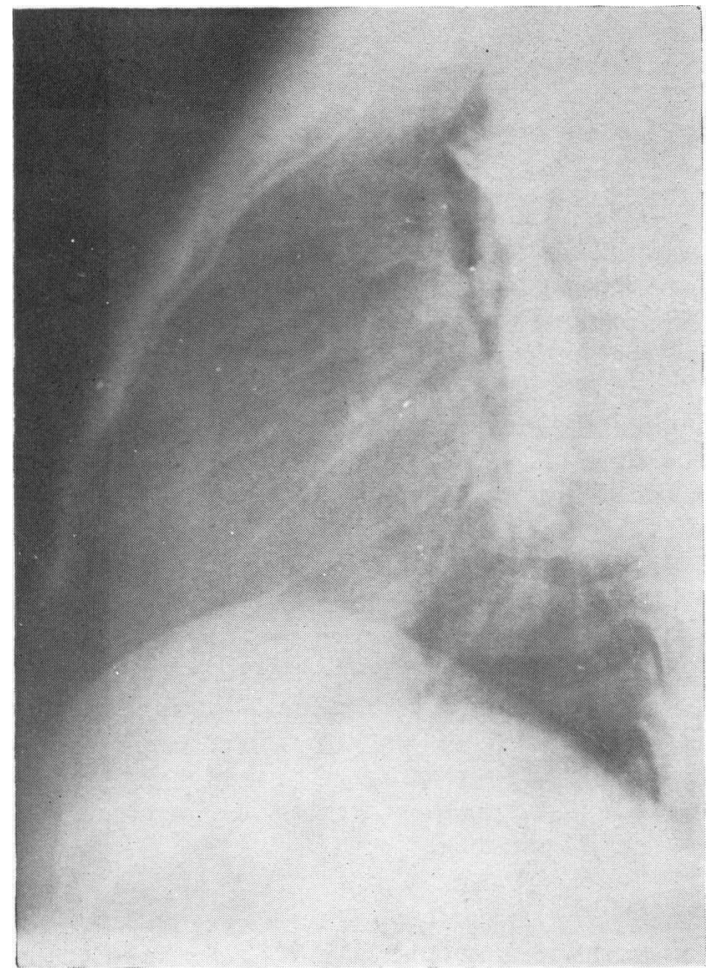

Fig. 2.-A.ortogram shows stenosis at the site of the anastomosis. the age of 2 years. The pre-operative brachial blood pressure was $200 / 110 \mathrm{~mm}$. Hg. The femoral artery was not palpable. He was completely asymptomatic at the time of follow-up; his performance was normal. An aortogram disclosed a slight stenosis (Fig. 2) at the anastomotic site. At the operation the circumference of the anastomosis had been $2.8 \mathrm{~cm}$. and that of the arch $3.4 \mathrm{~cm}$. Anatomical restoration of the aorta was less than ideal, and the picture taken at the operation shows unmistakable 'kinking' of the aorta (Fig. 3). Perhaps this kinking is partly

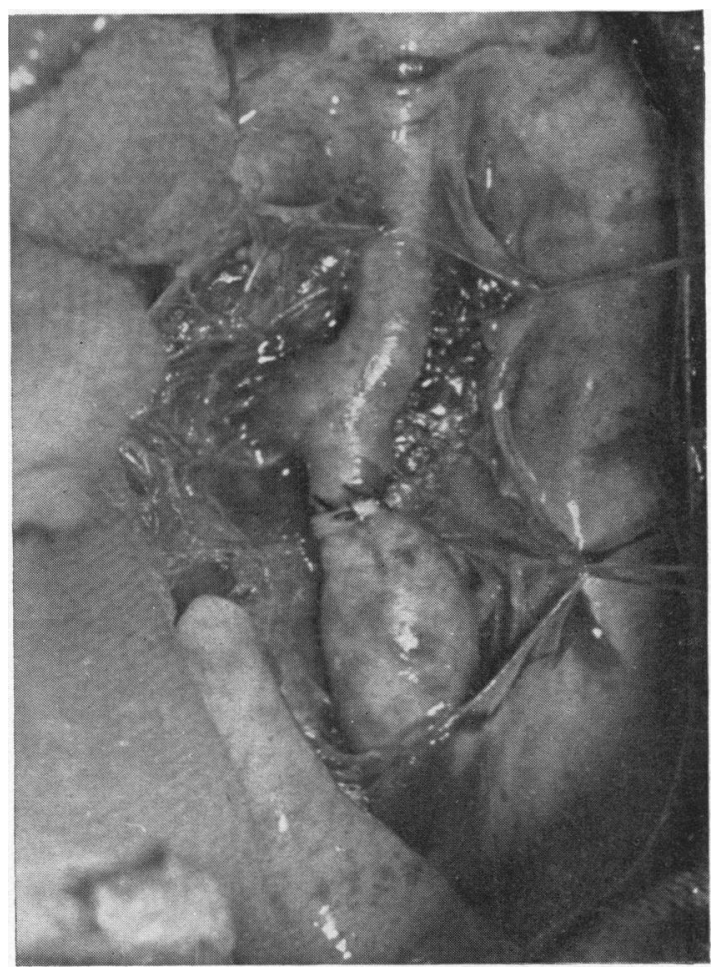

FIG. 3.-The anatomical restoration shown here is not ideal

responsible for the unsatisfactory result. In Leyden, therefore, efforts are made not only towards establishing the widest possible anastomosis but also towards optimal restoration of the normal shape of the aortic arch and isthmus.

Case B was operated on in 1957 as a boy of 8 years. At the operation it was found that the aorta between the subclavian artery and the ligamentum arteriosum was hypoplastic (Fig. 4). The collateral arteries were more strongly developed and gave some trouble. The hypoplastic part and the coarctation were resected and a latero-terminal anastomosis was made in which the aortic arch, subclavian artery, and 


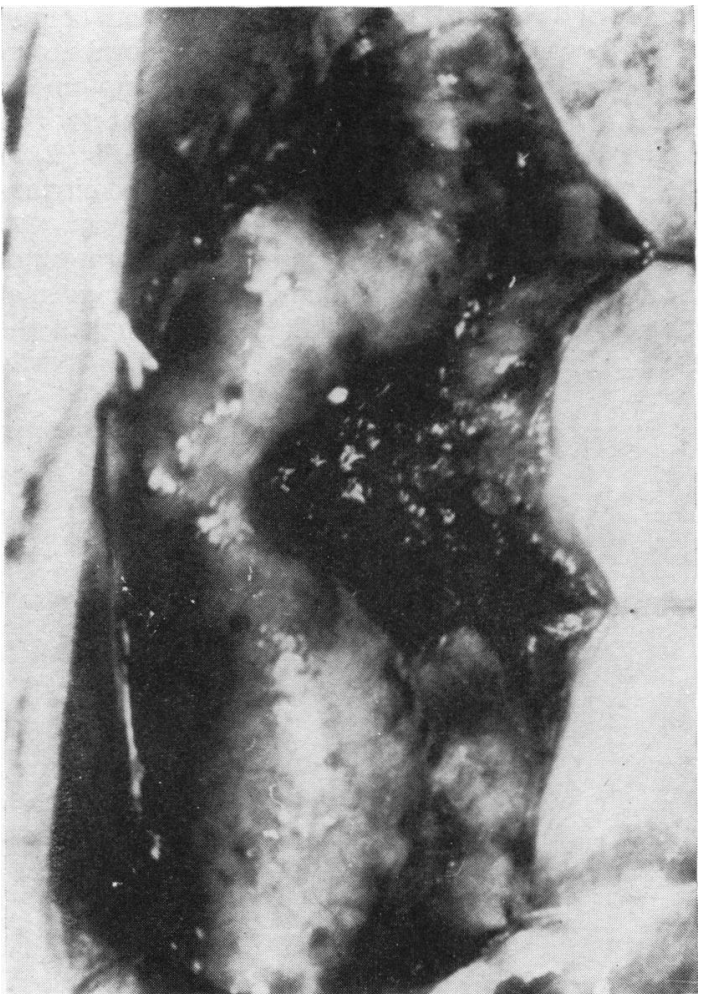

FIG. 4.-Hypoplastic aorta between subclavian artery and ligamentum arteriosum.

descending aorta together form a Y (Fig. 5). The circumference of the arch was $3 \mathrm{~cm}$., of the subclavian artery $3.9 \mathrm{~cm}$., and of the anastomosis $3 \cdot 4 \mathrm{~cm}$.

At follow-up the patient shows increasing symptoms of left ventricular hypertrophy, and the electrocardiogram and vectorcardiography indicate a valvular aortic stenosis with a slight insufficiency. He swims and used to play football but fatigues easily.

Reduction of Brachial Systolic Blood Pressure. If the brachial systolic blood pressure diminishes after resection of an aortic coarctation, the patient's expectation of life improves. The reduced brachial systolic blood pressure reduces the risk of a subarachnoid haemorrhage resulting from rupture of an aneurysm in one of the basilar arteries; and systolic blood pressure on effort is reduced (Taylor and Donald, 1960).

The pre-operative and post-operative brachial systolic blood pressure values are shown in Fig. 6, which indicates a post-operative decrease in all

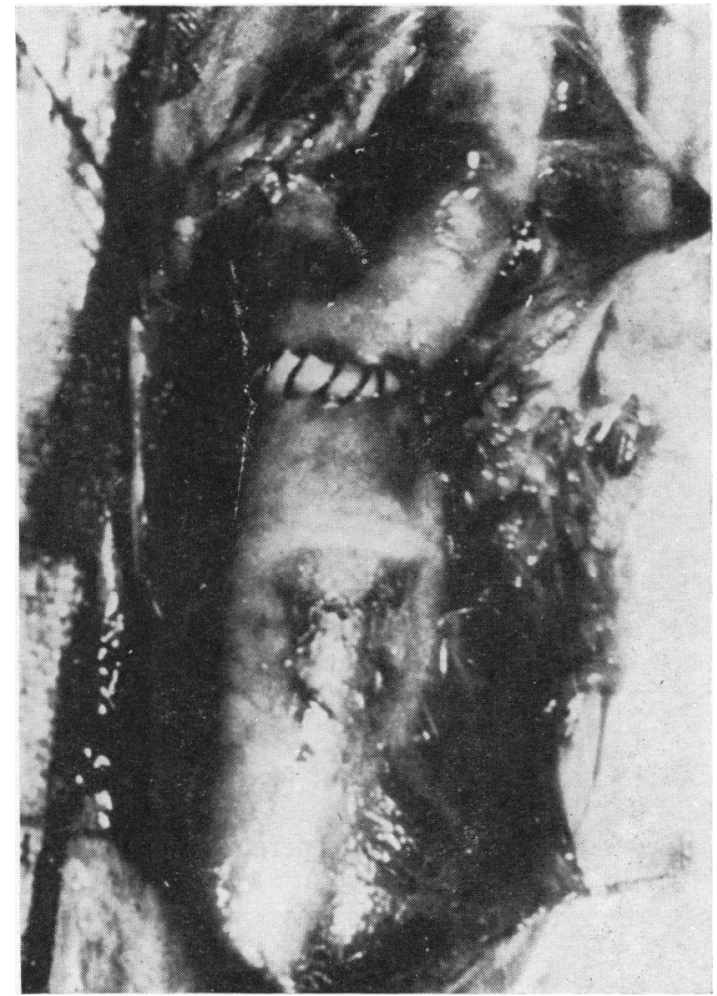

FIG. 5.-Reconstruction of aorta: subclavian artery and decending aorta together form a $\mathbf{Y}$.

cases where this pressure was greatly increased.

A striking feature is, however, that in 5 cases it still remained higher than $140 \mathrm{~mm}$. Hg. We have no explanation for this. Gelissen (1959) previously also observed that the decrease in systolic blood pressure in children was less pronounced than that in adults. The diastolic blood pressure in our patients was below $95 \mathrm{~mm}$. $\mathrm{Hg}$.

Reduction of Brachial Diastolic Blood Pressure. An increase in average blood pressure implies stress on the left ventricle. A high diastolic pressure means a high average blood pressure. Reduction of the diastolic blood pressure, therefore, improves the prognosis in these patients. The level of the diastolic blood pressure is shown in Fig. 7, which shows a post-operative decrease to $95 \mathrm{~mm}$. $\mathrm{Hg}$ or lower in all patients.

Subjective symptoms. Only a few patients had pre-operative complaints, such as pain in the legs on effort or frequent headaches. One patient was 


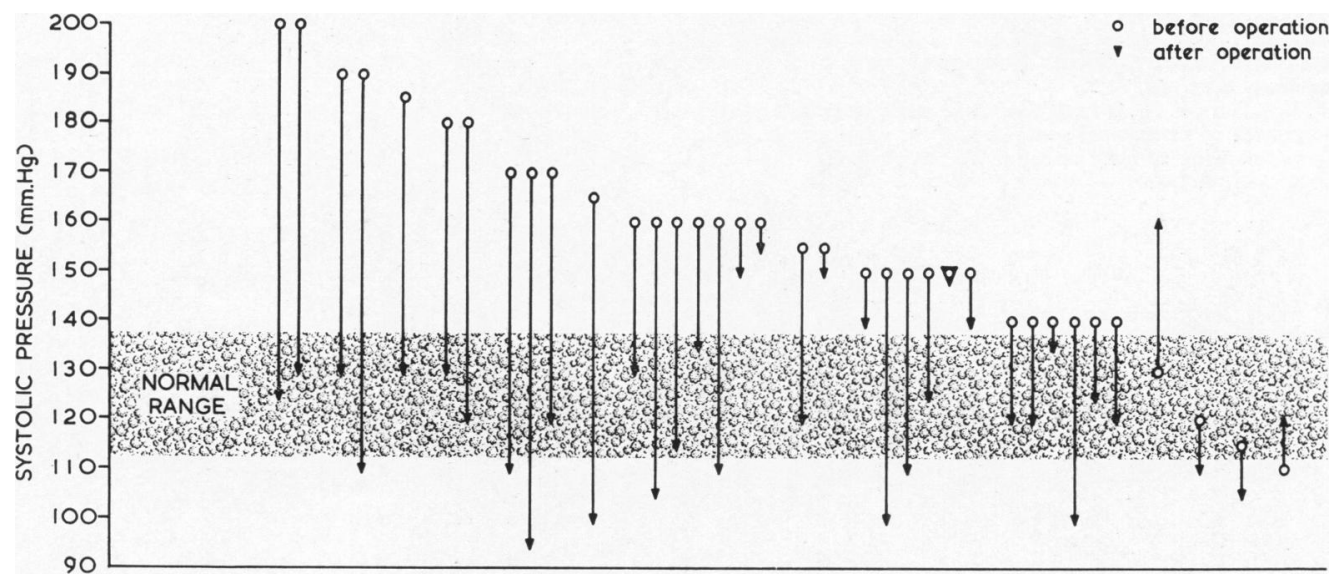

FIG. 6.-Decrease of systolic blood pressure after operation.

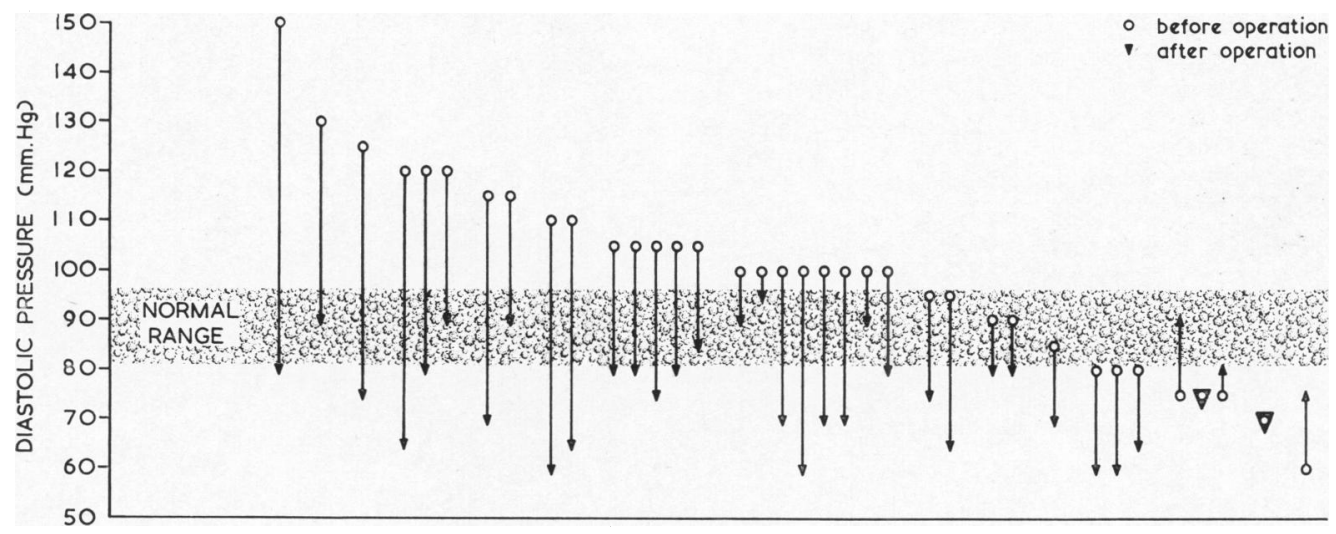

Fig. 7.-Decrease of diastolic blood pressure after operation.

unable to run. All patients were asymptomatic at the time of follow-up, except Case B already described.

These findings, however satisfactory, do not warrant the conclusion that the anastomosis does in fact participate in growth. To establish this, another follow-up on these patients after reaching adulthood is required.

\section{Summary and Conclusions}

A follow-up study was made of patients submitted to resection for coarctation of the aorta more than six years previously, and aged 12 or younger at the time of the operation. The object was to establish whether results remained good after completion of 
Morris, G. C., Jr., Cooley, D. A., de Bakey, M. E., and Crawford, E. S. (1960). Coarctation of the aorta with particular emphasis upon improved techniques of surgical repair. $J$. thorac. cardiovasc. Surg., 40, 705.

Moss, A. J., Adams, F. H., O'Loughlin, B. J., and Dixon, W. J. (1959). The growth of the normal aorta and of the anastomotic site in infants following surgical resection of coarctation of the aorta. Circulation, 19, 338.

Reifenstein, G. H., I.evine, S. A., and Gross, R. E. (1947). Coarctation of the aorta: a review of 104 autopsied cases of the "adult type", two years of age or older. Amer. Heart J., 33, 146.

Taylor, S. H., and Donald, K. W. (1960). Circulatory studies at rest and during exercise in coarctation of the aorta before and after operation. Brit. Heart J., 22, 117.

Waterston, D. J. (1961). Communication Annual Meeting Society of Thoracic Surgeons of Great Britain and Ireland. London. 